\title{
Psychological features of the relationship of personality resilience and subjective feelings of loneliness
}

\author{
Elena Tkach $^{1 *}$ \\ ${ }^{1}$ Pacific National University, Karl Marx Street, 68, 680000, Khabarovsk, Russia
}

\begin{abstract}
The article focuses on identifying and describing some aspects of the psychological characteristics of the relationship between personality resilience and the subjective feeling of loneliness in adolescence. Resilience is understood as a person's ability to adapt and be effective, to function successfully despite the influence of any external factors, to survive and develop. Resilience is presented as the ability to recover from setbacks, to rely on the gained life experience for your personal growth and selfrealization. An empirical study has shown that there is a strong inverse statistically significant relationship between the phenomenon of vitality and the subjective feeling of loneliness in adolescents. The experimental (correctional and developmental) work carried out was effective, as it influenced the development of the participants' resilience. The emphasis in correctional and developmental work was placed on the discovery and activation of the development of resources for self-care, a positive selfconcept, positive self-attitude, forward thinking, and the ability for longterm planning, the ability to cope, reflexive and communication skills and abilities, the ability to establish and develop connections with other people. The experimental work can be considered quite effective, since, according to the research participants, they began to cope with the negative aspects of loneliness, difficult life situations, became more positive and stable better.
\end{abstract}

\section{Introduction}

In the modern socio-cultural context, due to serious contradictions and difficulties for many people, the problem of experiencing loneliness and the acquisition of resources in order to effectively cope with it acquires a special status. In the case when a person with a pronounced introversion makes a choice in favor of the chosen loneliness, there are no difficulties. However, if loneliness becomes forced, the life of a person who is focused on communication and gains meaning through communication is painted in dark colors, vitality decreases, the person feels extremely uncomfortable. Such circumstances often become relevant for adolescents. In this regard, studies related to the search and discovery of various resources that allow a person to be productive, quickly overcome the emerging uncomfortable psychoemotional states, and live a full life are of keen interest. One of these resources, of course, is resilience.

\footnotetext{
* Corresponding author: demidenkoes@mail.ru
} 


\section{Materials and methods}

Resilience in their research has been actively studied by various authors in the field of psychology [1-16]. These researchers describe resilience as a personality trait that provides, largely determines how a person copes with stress, life pressure, blows of fate, life challenges, excessive pressure, problems arising despite the circumstances of existence.

It should be noted that resilience provides a person with vitality, the necessary elasticity, endurance, optimism, a predisposition to risk, confidence, and resilience in difficult times when a person is faced with the experience of serious stress in dramatic or tragic circumstances (family problems, difficulties with health, difficulties at work, financial problems, etc.). It is precisely resilience, according to many researchers, that allows a person to quickly come to their senses when faced with difficult life experiences, flexibly, resiliently respond to difficult life circumstances and exclusive situations.

Resilience is manifested as the ability to adapt and be effective, to maintain one's integrity, to function successfully despite the influence of any external factors, to survive and develop, it is the ability to recover from failures, to rely on the gained life experience for personal growth and self-fulfillment, it is the ability to succeed, relying on personal resources, competencies, behavioral strategies and using them productively in difficult life situations.

Resilience allows a person to carry out his life activity at the level of subjectivity, that is, to be actively aware of the constancy of his I, to effectively manage his behavior in accordance with the norms, laws and rules, to have positive criticality in relation to himself and his actions, to be productive in planning his life ways and implementation of your plan. An important aspect of the manifestation of human resilience is the discovery of the ability, if necessary, to change their behavior, showing flexibility and adaptability, clarifying the meaning of their actions and their existence depending on changing conditions.

For resilient individuals, a positive sense of oneself and a positive attitude towards oneself as a person who copes with emerging difficulties, confident reliance on existing personal and social resources, a tendency to altruistic and prosocial behavior, a developed ability to find meaning in traumatic experience and productively overcome trauma are relevant, to live a fulfilling life. after trauma, active social interaction.

Resilience can be viewed as a person's competence - the ability to adapt and develop in rapidly changing life circumstances.

Addressing the problem of loneliness, we understand that loneliness is experienced in different ways by different people. For many, loneliness is not a sign of weakness or vulnerability. But there is a category of the population that needs specially organized psychological support (psychological support) in the circumstances of the experience of forced loneliness, as it causes deep stress.

In our study, we turn to the study of the correlation between the phenomena of resilience and loneliness in adolescents.

Bikreeva Angela, a student of the Faculty of Psychology and Social and Humanitarian Technologies of the Pacific State University, took an active part in organizing and conducting the empirical research presented in this article.

The aim of the study is to identify and describe the psychological characteristics of the relationship between the resilience of the individual and the subjective feeling of loneliness in adolescence.

Formulating the hypothesis, we assumed that in adolescents (boys and girls) there is a relationship between the phenomenon of resilience and the subjective feeling of loneliness; for those of adolescence with a high level of resilience, a low level of subjective experience of loneliness is relevant. 
The empirical study used:

1) questionnaire of human resilience (author E.A. Rylskaya). This questionnaire is designed to assess the indicator of a person's vitality as an integral ability to preserve their own systemic integrity, which allows them to successfully solve basic life tasks. The questionnaire contains 106 questions. There are 4 possible answers "yes", "rather yes than no", "more likely no than yes", "no". There are 4 scales in the questionnaire: "ability to adapt", "ability to self-regulation", "ability to self-development", "meaningfulness of life." The sum of all these scales represents the overall vitality score. The expressed indicators according to the questionnaire mean the ease of adaptation to the existing requirements and assessment criteria in society through the assignment of norms and values of society, indicate independence and flexible response to changing conditions, independence, ease of mastering new activities, confidence and success. High vitality, according to the author of the questionnaire, correlates with a person's desire to know and improve himself, his conviction that everything that happens to him contributes to his development due to the knowledge gained from experience. Such a person is ready to act even in the absence of reliable guarantees of success, considering a simple desire for psychological comfort and personal safety impoverishing human life. The approbation of the questionnaire made it possible to assert that it is a reliable and valid means of psychological diagnostics, the results of which do not depend on the sex of the subjects;

2) Test questionnaire "Scale of subjective feeling of loneliness" D. Russell, L. Peplo, M. Ferguson (adaptation by N.E. Vodopyanova). The test questionnaire is designed to determine the level of loneliness and social isolation of a person. The identified state of loneliness can be associated with anxiety, social isolation, depression, boredom. The phenomenon of loneliness lies in the fact that the feeling of loneliness is perceived as an acutely subjective, purely individual and often unique experience. One of the most distinctive features of loneliness is the specific feeling of being completely immersed in oneself. The questionnaire includes 21 statements to which you need to answer "often", "sometimes", "rarely", "never". The number of each of the answer options is calculated. The sum of the answers "often" is multiplied by three, "sometimes" by two, "rarely" by one, and "never" by 0 . The results are added together. The maximum possible indicator of loneliness is 63 points.

For statistical processing of the results obtained in the empirical study, the method of mathematical statistics (Spearman's rank correlation coefficient in the Microsoft Excel software environment) was used.

Empirical research base: Pacific State University (Khabarovsk, Russia).

The empirical study involved 100 respondents, including 72 girls and 28 boys, all of them Russians aged 18 to 23 years.

The empirical study included several sequential stages:

1) The first stage - the stage of selection of psychodiagnostic tools;

2) The second stage - carrying out psychodiagnostic procedures;

3) The third stage - discussion and analysis of the results of primary diagnostics;

4) The fourth stage - the organization and implementation of experimental work;

5) The fifth stage - discussion and analysis of the results of experimental work.

\section{Results}

The results of the conducted psychodiagnostics made it possible to identify groups of adolescent respondents with different levels of severity of resilience and a subjective feeling of loneliness.

According to the questionnaire of E.A. Rylskaya revealed the following picture: 
- $43 \%$ of the study participants have a high level of vitality;

- $28 \%$ of the participants in the study have an average level of severity of viability;

- $298 \%$ of study participants have a low level of vitality

According to the "Scale of subjective feelings of loneliness" it was revealed that:

- A high level of severity of the subjective feeling of loneliness is relevant for $21 \%$ of the study participants;

- The average level of severity of the subjective feeling of loneliness is relevant for $44 \%$ of the study participants;

- A low level of severity of the subjective feeling of loneliness is relevant for $35 \%$ of the study participants.

The use of the method of mathematical statistics (Spearman's rank correlation) confirmed the presence of a strong inverse statistically significant relationship between the phenomenon of vitality and the subjective feeling of loneliness among the respondents who took part in the empirical study $(\mathrm{p}=-0.7067)$.

Testing the hypothesis put forward, we drew attention to the results of psychodiagnostics of a group of subjects with a high level of resistance. The data obtained are shown in Figure 1.

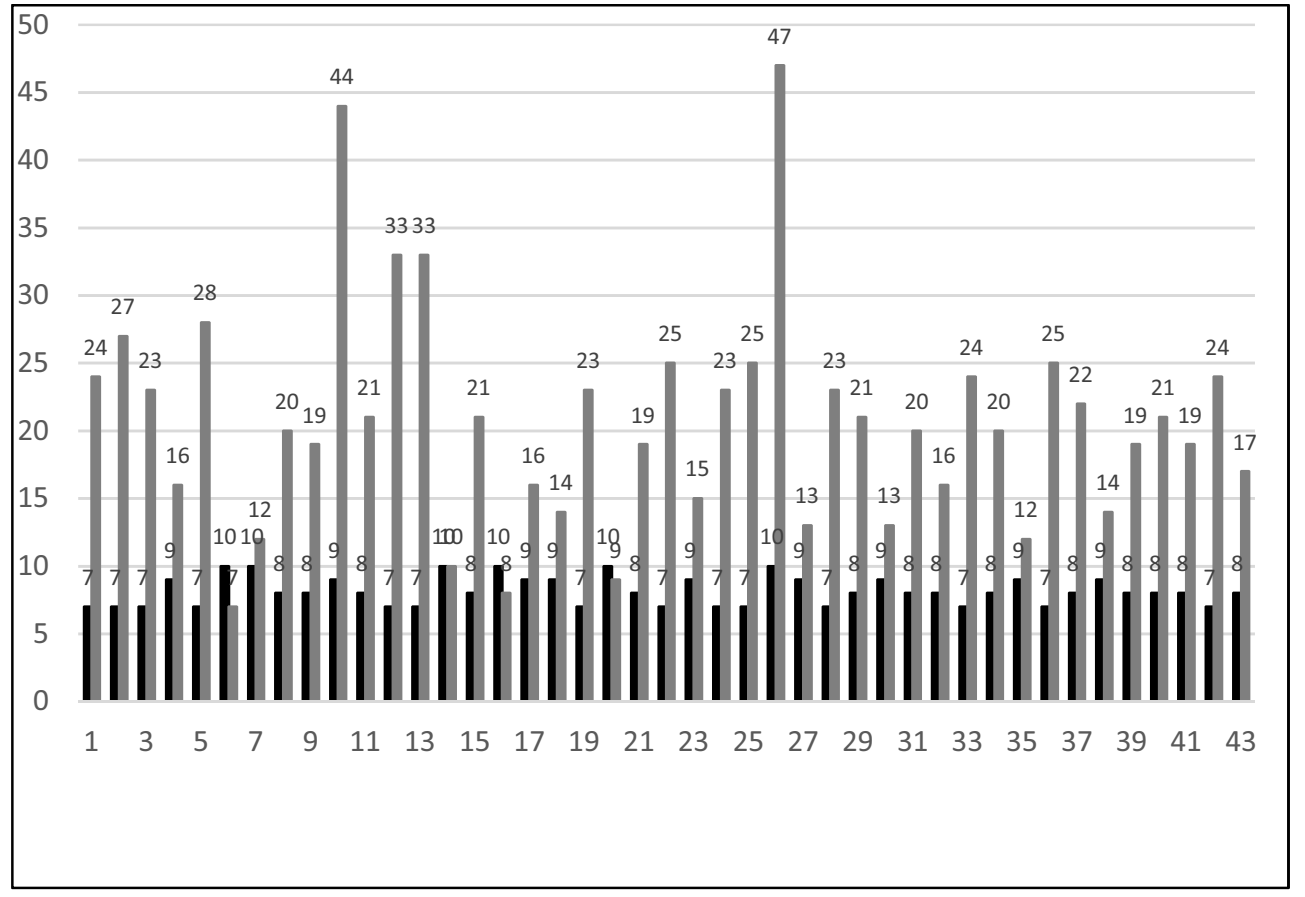

Fig. 1. Results of psychodiagnostics (group of respondents with a high level of resilience, $n=43$ ).

Note. The black color on the diagram indicates the severity of resilience; light gray color denotes the severity of the subjective experience of loneliness of the participants in the empirical study.

In the presented diagram, we see two particularly prominent values: 44 and 47 points on the Scale of subjective feeling of loneliness with a high level of vitality 9 and 10 (according to the questionnaire of E.A. Rylskaya). In a psychological conversation with these two participants in the empirical study, it was revealed that, despite the general positiveness of their lives, they often feel lonely in their souls. 
It should be noted that in the group of respondents with a high level of resilience:

- A high level of subjective feeling of loneliness was relevant for 2 people $(4.65 \%$ of the sample),

- The average level of subjective feeling of loneliness was relevant for 14 people $(32.56 \%$ of the sample),

- A low level of subjective feeling of loneliness was relevant for the majority of respondents -27 people $(62.79 \%$ of the sample).

\section{Discussions}

Based on the results of the initial diagnosis, 20 respondents were invited to take part in a specially organized work aimed at increasing the level of resilience, but only 4 responded (three girls and one boy). This can be explained by the fact that not every person is ready to rethink and change their attitude to their life and the world around them. Here are some of the named reasons for refusal: "I'm not doing badly anyway," "I'm not ready for serious changes," "I don't have time for unnecessary reflections."

The age of the study participants who agreed to take part in the experimental (correctional and developmental) work ranged from 20 to 23 years. It is noteworthy that the young man himself showed great interest in the results obtained and in how the level of resilience could be increased.

Experimental (correctional and developmental) work was carried out within a month. The participants in the experimental group (group of meetings) performed various kinds of tasks, followed certain psychological recommendations, had the opportunity to actively reflect and discuss the ongoing changes in other participants. The emphasis in correctional and developmental work was placed on the discovery and activation of the development of resources for self-care, a positive self-concept, positive self-attitude, forward thinking, and the ability for long-term planning, the ability to cope, reflexive and communication skills and abilities, the ability to establish and develop connections with other people.

In the context of the experimental work, elements of bibliotherapy and art therapy were used.

The participants in the experimental study were given the opportunity to comprehend and discuss important moments of their lives with an orientation to such literary texts as "Pollyanna" by Eleanor Porter, "The Last Elf" by Marie de Sylvanas, "Fight for Fire" by J. Ronnie Sr., "Daisy Fey and Miracles" Fannie Flagg, The Boy Who Swam with Piranhas, David Almond, Howl's Moving Castle, Diana Wynn Jones, White on Black, Ruben Gallego, Forever Alice by Lisa Jenova, Sailor's Song by Ken Kesey.

As we can see from the data presented in the diagram (Figure 2), in the course of secondary diagnostics in the experimental group after carrying out correctional and developmental work, an increase in the level of resilience was revealed in all participants in the experimental study. 


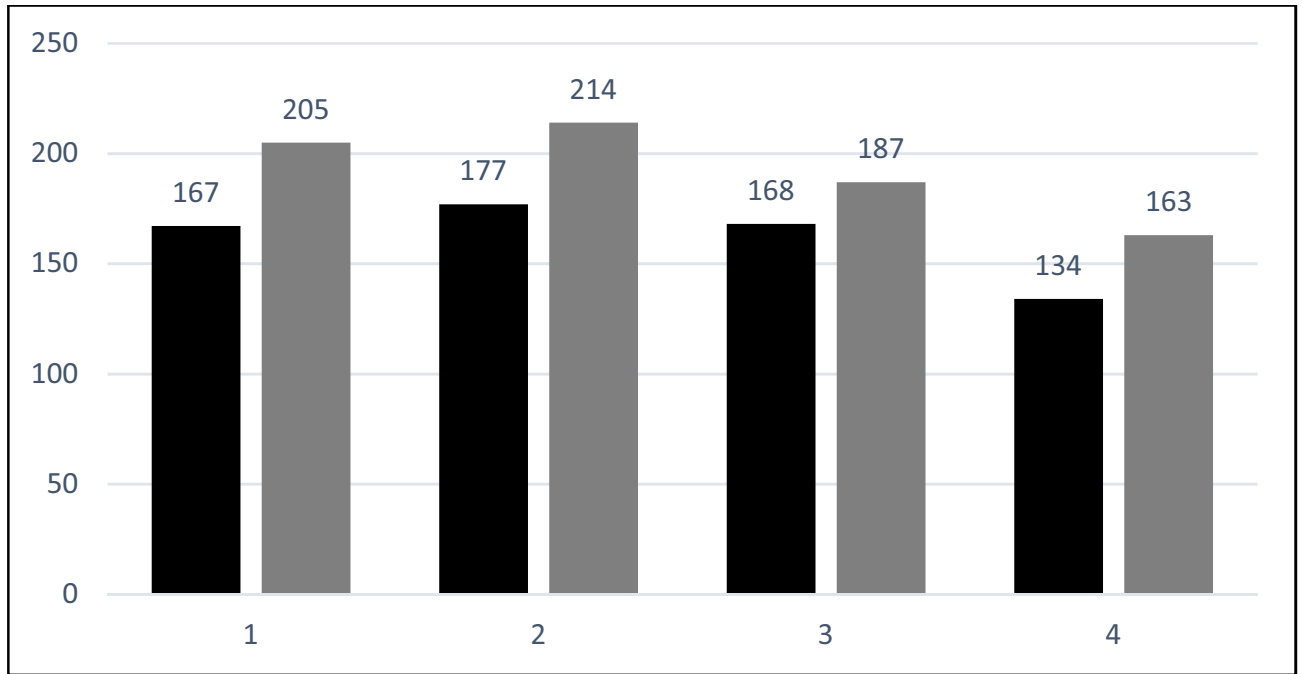

Fig. 2. Dynamics of changes in the severity of resilience among participants in correctional and developmental work $(n=4)$.

Note. The black color on the diagram denotes the severity of resilience, identified by the results of the primary diagnosis; light gray color indicates the severity of resilience based on the results of secondary diagnostics.

The analysis of the participants' reflective self-reports showed the following. In their opinion, the strengthening of self-confidence, the acquisition of assertiveness and congruence became significant for the development of the resilience of the participants in the experimental study. Participants in the experimental study learned to pay more attention to their needs and feelings, take care of themselves, notice their positive qualities and achievements, cope with stress, effectively overcome fears and anxiety, focus and concentrate on the positive aspects of life and relationships with different partners and opponents in interaction, set goals and move towards them. According to the participants in the experimental study, they began to better cope with the negative aspects of loneliness, difficult life situations, became more positive and stable.

\section{Conclusion}

Summing up, the following conclusions can be formulated:

- resilience is such a personality trait that determines how a person copes with stress, life pressure, blows of fate, life challenges, excessive pressure, problems that arise despite the circumstances of existence, an important aspect of the manifestation of a person's resilience is finding the ability, if necessary, to change their behavior, showing flexibility and adaptability, clarifying the meaning of their actions and their existence, depending on changing conditions.

- loneliness is experienced in different ways by different people, for many loneliness is not a sign of weakness or vulnerability, but there is a category of the population that needs specially organized psychological support (psychological support) in the circumstances of experiencing forced loneliness, as this causes deep stress.

- There is a strong inverse statistically significant relationship between the phenomenon of vitality and the subjective feeling of loneliness in adolescents who took part in an empirical study, 
- the carried out experimental (correctional and developmental) work was effective, as it influenced the development of the participants' resilience; the emphasis in correctional and developmental work was placed on the discovery and activation of the development of resources for self-care, a positive self-concept, positive self-attitude, forward thinking, the ability for long-term planning, the ability to cope, reflexive and communication skills and abilities, the ability to establish and develop connections with other people.

- in an experimental study, participants learned to pay attention to their needs and feelings, take care of themselves, notice their positive qualities and achievements, cope with stress, effectively overcome fear and anxiety, focus and concentrate on the positive aspects of life and relationships, set goals and move towards him;

- the work carried out can be considered quite effective, since, according to the research participants, they began to better cope with the negative aspects of loneliness, difficult life situations, became more positive and stable.

\section{References}

1. S.N. Vasilyeva, E.A. Rylskaya, Yaroslavl Pedagogical Bulletin, 2 (107), 106-113 (2019) DOI: 10.24411 / 1813-145X-2019-10358

2. L. G. Dikaya, A. V. Makhnach, A. I. Laktionova, Social and Humanitarian Sciences in the Far East, 15, 4, 137-146 (2018) DOI: 10.31079 / 1992-2868-2018-15-4-137-146

3. A.V. Makhnach, A.I. Laktionova, Yu.V. Postylyakova, Social and Humanitarian Sciences in the Far East, 15, 4, 45-54 (2018) DOI: 10.31079 / 1992-2868-2018-15-445-54

4. A.V.Makhnach, International Journal Of Adolescence And Youth, 21, 2, 195-214 (2016) DOI: 10.1080/02673843.2013.815116

5. A.V. Makhnach, Bulletin of the Russian State University for the Humanities. Series: Psychology. Pedagogy. Education, 2, 37-50 (2019) DOI: 10.28995 / 2073-6398-20192-37-50

6. A.V. Makhnach, Bulletin of the Kostroma State University. Series: pedagogy. Psychology. Sociokinetics, 25, 2, 46-51(2019) DOI: 10.34216 / 2073-1426-2019-25-246-51

7. A.V. Makhnach, Psychological journal, 38, 4, 5-16 (2017) DOI: 10.7868 / S0205959217040018

8. B. Daniel, S. Vincent, E. Farrall, F. Arney, International Journal of Child \& Family Welfare 1, 2-21 (2019)

9. A.J. Zautra, J.S. Hall, K.E. Murray, Resilience: A new definition of health for people and communities. Handbook of Adult Resilience (New York, London: Guilford Press, 2010)

10. D. Fletcher, M. Sarkar, European Psychologist, 18, 12-23 (2013) DOI: 10.1027 / 1016 9040 / a000124

11. O. Hjemdal, O. Friborg, S. Braun, P. Fossion, International Journal of Testing, 11, 5370 (2011) DOI: 10.1080 / 15305058.2010.508570

12. T.D. Letzring, J. Block, D.C. Funder, Journal of Research in Personality, 39, 395-422 (2005) DOI: 10.1016 / j.jrp.2004.06.003

13. G. Windle, D.A. Markland, R.T. Woods, Aging and Mental Health, 12 (3), 285-292 (2008) DOI: 10.1080 / 13607860802120763 
14. I. Strnadova, RevistaComplutense de Educación, 17 (2), 35-50 (2006)

15. I. Salisu, N.Hashim, IOSR Journal of Business and Management (IOSR-JBM), 19, 4, III, 23-33 (2017) DOI: 10.9790 / 487X-1904032333

16. W.J. Smith, et al, International Journal of Behavioral Medicine, 15, 194-200 (2008) DOI: $10.1080 / 10705500802222972$ 